\title{
The Manifestation of Will: The Vectorial Force of Accepting Guilt
}

\author{
Camil Tanasescu \\ "Dimitrie Cantemir" Christian University of Bucharest, Faculty of Juridical and Administrative Sciences, Romania, \\ camiltanasescu@gmail.com
}

\begin{abstract}
Individual conduct involves the orientation of actions in a certain way by making a decision. The attempt to establish the unique and appropriate purpose of the action is based on the intention to achieve that goal, followed by the elaboration of the mental plan for the realization of the action. In the deliberation, certain processes are underway to investigate the conditions for carrying out the criminal activity, assessing its effects in the objective reality. Following the analysis of the meanings, the reasons and the purpose pursued, the mental plan for the concrete realization of the criminal activity is finalized by making the decision to commit the crime. Finalizing the decision is followed by its execution to achieve the goal pursued, the aggressor using is hull psychophysical ability, knowledge, skills and ability in adopting a method of action. The manifestation of will is realized when the individual acts knowingly, even if the purpose of his actions coincides with the interests and needs of others. The guilt appears to be a force contrary to the manifestation of freedom of each individual, considered as the original behavioral form of any collectivity that opposes block of opposite behavior.
\end{abstract}

KEYWORDS: aggressor, behavior guilt, crime, individual need, intention, social need, will

\section{Introduction}

Among the main faculties of man - sensitivity, intelligence and will, the latter creates violently. The voluntary act is preceded by a person's reflection on how to proceed with the action and on the decision to execute the action (Sillamy 1996, 341). Behaviors that do not meet these requirements do not depend on the will of the individual and are not considered to be composed of volitional acts. For the responsible person, the volitional act finds a state of dynamic (biological and psychological) balance in the context of reporting behavior to social rules (Lăzărescu and Ogodescu 2011, 21).

Guilt denotes the perpetrator's subjective attitude towards action - inaction committed with intent or guilt, as well as its outcome (Dongoroz 1969, 189). Human activity is an innate tendency that underlies all behaviors, all events taking place are spatially and temporally determined.

\section{The conceptualization of will, the embryonic form of guilt}

The instinctual and emotional levels have their own dynamic energy, which can trigger a behavior. Unlike the former, cognitive and spiritual-value levels, not having an efficient energy substrate, must be sustained by will to trigger behaviors. Motivational instances are those forces capable of generating behaviors. They are represented by: affective wishes, cognitive interest and curiosity, volitional will, and aspirations at a spiritual-value level.

The rational decision is, however, low energy loaded towards instincts and affectivity. This is the will. If the will is weak, the decision will not be put into action, but if the will is strong, it goes to act. The move to act must be sustained in order to achieve the goal. Will has to make persistence in action.

The will can control the personal need, the harm it is for the criminal to accept the guilt. The psychical processes of the guilt are carried out in the inner force of the active subject of the crime and become relevant through its external manifestations. These processes are only those that constitute the common psychic substrate of any human act.

In normative theory, guilt has a very close meaning to the one it attributes to it the psychological theory (which dominates our criminal thinking), because it claims to express one report of contradiction between the will of the agent and the will of the lawyer or, in other terms, it expresses. 
The "reprehensible character" (Tănăsescu 2014a, 78) of the attitude of the agent towards the social values protected by criminal law, in contrast, a highly controversial issue and confusing remains, and in normative theory, that of the meaning of the concept of "subjective element".

The notion of subjective element designates, according to a unanimous point of view accepted in our doctrine (Dongoroz 1939, 230; Bulai 1997, 188; Oancea, 1971, 183; Mitrache 2016, 94), the agent's mental attitude towards the committed act and its consequences, an attitude that must be embraced for the crime to subsist, form the guilt (intent, fault) required by law.

The sense of determination of the action committed by the will requires that each willful act be the result of a previous volitional act, and that of another volitional act, ad infinitum (Ryle 1949, 113), thus forming a chain of volitional acts connected by them by the necessities called, which subsequently transforms into oblivion, passions, desires, lusts. In the absence of creativity, everything is habitual.

The need to establish the inherent connection between the will and action or inaction implies the individual's responsibility for his actions or inactions, as a result of individual freedom in achieving the purpose by committing the crime, as well as responsibility (the obligation of the state that protects social values by the norms issued) of establishing the criminal guilt, as a result of the danger to the legal object.

Acts of will depend on the conviction of the individual, being the resultant force of the interaction of psychic and emotional processes, having a certain form, meaning and certain meanings highlighted through the individual's conscious criminal actions and actions.

\section{The manifestation of the criminal will - the giant step towards accepting the guilt}

The manifestation of the will is accomplished when the individual acts knowingly even if the purpose of his actions conflicts with the interests and needs of others. Voluntary actions may be influenced by the hierarchy of reasons underlying momentum, driven by a contradiction of motivational factors. This state of conflict leads to the establishment of guilt. Therefore, in the absence of will or in the case of its vitiation, in terms of motivation, the perpetrator of a crime will not be liable for damaging effects.

The object of guilt is, essentially, the cumulating of the two factors: intellectual and volitional. The absence or impairment of any of them leads to the non-existence of guilt, by virtue of the principles of criminal liability.

The appearance of will involves the existence and passage of the intellectual factor into the volitional, the extension of the intellectual state in the volitional state as a form of human attitude (Aniței, Chraif, Burtăverde, and Mihăilă 2016, 78). The intellectual factor also determines the triggering of the voluntary factor, in order to identify the conditions for committing the criminal act, as well as to assess its socially dangerous effects. By knowing how the action (inaction) and its results will evolve, the killer will act in a characteristic way. Knowing the external stimuli that make up any behavioral act is to adopt an appropriate response to the purpose and the mobile pursued by the killer.

\section{Legal will is a form of psychological will bombarded with the intention of producing legal effects}

The psychological element revealed by the external manifestation of the active subject is only a premise from which the legal appreciation starts, in order to reach the rational will, the logic, which constitutes the true foundation of law. Law requires an interpretation of the facts, of the external manifestation of the individual in accordance with what command reason, the only one able to place each personality on the same plane with the others and to create equality, which is inherent to the idea of justice.

The unlawful act is defined as a concrete act (Antoniu 1995, 54) that violates the legal provisions or rules of conduct required by law to be observed. The norms of conduct are related to the order of fundamental social values, in the sense that they impose specific individual conduct, and by structuring in the system of criminal law the society, the state as its representative, interests (criminal illicit is different from other forms of illicit - civil, contravention - because it harms the most important social values - state security, life, health, dignity, person's wealth -, and the resulting products are socially dangerous). 
Like any human creative act, the offense, even if it has a negative social character, goes through several phases and in the individual psychic life: voluntary imagination - when the person consciously proposes (sometimes interfering with unconscious associations) to do an action - inaction socially dangerous one involving a spontaneous attitude or a long-term physical, mental and psychological effort; the stage of preparation - when the person is informed, observes, delimits the mobile and the purpose, adopts the plan; the trial phase - when the person tries different solutions, attitudes, inconclusive and unsatisfactory states; the stage of conception, the intuition of concrete action through the elucidation of the objectives and the awareness of the components of the action plan; the stage of realization - when the person commits the deed, executes the set of elements that make up the action plan, organized in a succession of rationalizations concretized in actions - illicit inaction; the verification stage - when the person verifies the actual implementation of the action plan originally designed and tries to take steps to remove the possibility of identifying him as the perpetrator of the crime.

Clearly, any action - inaction - is explained by the active role of the will to support the internal, preparatory phase of conception of the action plan, as well as the external phase of concrete execution.

Guilt is a manifestation of consciousness and will that actively accompanies a person's actions and which consists in the person's psychic attitude towards his action or inaction in the sense of knowing the facts that the act is provided by the criminal law, dangerous, whether they want them, whether they accept it or manifest indifference.

Although guilt - which is an "essential feature" (Romanian Criminal Code 2009, art. 17) of any crime - can and should either established in both formal and in-kind offenses specific to the latter the offense is that the guilt does not exhaust the constitutive content of the offense, because in this case, it becomes necessary to prove, in addition, the existence of a report of causality between the act of guilty and the unlawful result.

The requirement to establish the concrete existence of a result identical to that described in the model legal ("typical result") logically raises the requirement to prove that there is a causal link between the killer's (inaction) action and "typical outcome".

Apparently tautologically, power is strong because it produces positive effects on its inseparable platforms: that of wishes and that of knowledge.

Power arises in the moment of amplitude of social normative intransigence, taking the expression of decision, the capacity to manage contradictions, and the relationship between social action and norm. When an individual is not necessarily linked to cultural determinants of his social identity, he can counter the social order and its codes an asocial attitude, a hybrids. This anarchic tendency of the individual to assume himself as absolute, as a self-sufficient narcissistic entity, does not abolish socialization in the construction of his identity, since recognition is his essential condition. (Padovani 1990, 153).

Thus, the individual, subjective, and extrinsic capacity to establish intersubjective social relations is configured. To this dimension of power is added an objective, structural level, in which the contradictory management function appears as a mechanism registered in the institutional normative order.

Social conflicts are the source of imbalance and tension, of socio-individual confrontations both mentally and physically (The basic idea in explaining conflicts is to challenge a social interaction that even if the confrontation between contestants does not quench will determine the cognitive progress for the change of the individual or the social system in which it evolves).

The conflict between the criminal and the legal norm enshrined and adopted precisely in order to ensure the exercise of the rights of the other individuals determines two possibilities: the social reformation of the individual by punishment or the reformation of the punishment system by removing the norms of criminalization, tightening or reducing the sanctioning role of punishment.

The guilt defines the person's mental attitude towards the concrete action and implicitly against the result of the violation, ignoring, the legal norm is eluded (Tănăsescu 2014b, 183). The realization of the illicit act (crime) implies the meeting of the two factors: consciousness (intellectual) and will (volitive), which are in a close connection (Antoniu 1995, 37). The neurosensory capacity of the 
individual determines and expresses the ability to perceive the outside world in a quick and detailed manner so that conscious acts are correlated and involved in social behavior. From the perspective of understanding social demands, the structure of individual behavior must follow that of accepting individual responsibility in which the moral appreciation of each act committed is found.

The voluntary factor designates the organization of individual behavior focused on the objectification of the decision taken to achieve the concrete purpose. The voluntary act does not appear in a pure form, but it is based on the phases that make up the intellectual factor, uniting itself into a whole action because the action will not exist without a prior awareness of how to achieve the resulting consequences. Within certain limits, it is obvious that the intellectual factor contributes to the formation of the adaptive capacity of the action model, the individualization of the will, as well as the appreciation of the degree of guilt.

\section{Conclusions}

In conclusion, the guilt is designed so that the killer is held accountable for the intention, guilt or neglect manifested. The guilt exists, however, only in the case of the conscious will, objected by the criminal to the action - the inaction committed.

Establishing guilt involves a comparison of how the person concerned should act in relation to the requirements of the law and the way of effective action, by taking into account all the circumstances in which the detrimental act has occurred, all the objective and subjective factors that they have generated.

The absence of guilt in the private law branches exonerates the person from liability but does not release it, as in the public law sectors. Solving the problem of guilt in the branches of law will greatly contribute to solving another problem, no less important, concerning the institution of responsibility, which will ultimately bring about real changes in the system of social-juridical values of our society.

\section{References}

Aniței, Mihai, Mihaela Chraif, Vlad Burtăverde, and Teodor Mihăila. 2016. Personality Psychology Treaty. Bucharest: Three Publishing House.

Antoniu, George. 1995. Criminal Offense, Bucharest: Academia Publishing House.

Bulai, Costică. 1997. Criminal Law Handbook, Bucharest: All Publishing House.

Dongoroz, Vintilă. 1939. Criminal Law. Bucharest: Socec Publishing House.

Dongoroz, Vintilă. 1969. Theoretical Explanations of the Romanian Criminal Code. The general part. Bucharest: Academic and Pedagogical Publishing House.

Lăzărescu, Mircea, and Doru Ogodescu. 2011. Psychiatric Guide, Timișoara: Helicon Publishing House.

Mitrache, Constantin. 2016. Romanian Criminal Law. General part. Bucharest: Universul Juridic Publishing House.

Oancea, I. 1971. Criminal Law, General Part. Bucharest: Didactic and Pedagogical Publishing House.

Padovani, T. 1990. Diritto Penale. Milano: Giuffre Editore.

Romanian Criminal Code, Law no 286/2009 on the Criminal Code Official Gazette no. 510 of 24.07.2009.

Ryle, Gilbert. 1949, The Concept of Mind. Chicago: University of Chicago Press.

Sillamy, Norbert. 1996. Dictionary of Psychology, "Larousse” Collection, Univers Enciclopedic Publishing House.

Tănăsescu, Gabriel. 2014a. Analytical Criminology, Craiova: Sitech Publishing House.

Tănăsescu, Gabriel. 2014b. Criminal Law. General Part, Vol. I. Craiova: Sitech Publishing House. 